\title{
Research Article \\ Study of Alloying Process on 40Cr Surface with Electron Beam after Electroplated Cr Layer
}

\author{
Xu Hongbin, Hu Jianjun, Li Hui, Mao Rongshan, Sun Fei, and Hou Tianfeng \\ Chongqing University of Technology, Chongqing 400054, China \\ Correspondence should be addressed to Hu Jianjun; hujj@qq.com
}

Received 13 July 2013; Accepted 11 September 2013

Academic Editor: Xing Chen

Copyright (c) 2013 Xu Hongbin et al. This is an open access article distributed under the Creative Commons Attribution License, which permits unrestricted use, distribution, and reproduction in any medium, provided the original work is properly cited.

\begin{abstract}
The electroplated hard chromium coat was selected as precoating to improve surface properties of $40 \mathrm{Cr}$. Then electron beam alloying process was experimentalized. The relation rules were summarized between alloying process parameters and overall surface properties by surface morphology observation, surface energy spectrum analysis, EDX analysis in section, and XRD. Experiment results showed that the microcracks appeared on surface of electron beam alloying specimen. Microcracks could disappear when the orthogonal experimental optimum process was used. The matrix metal elements diffused into metal coating surface after electron beam treatment. The maximum depth of alloyed layer could reach $8 \mu \mathrm{m}$ after electron beam alloying treatment, and electron beam alloying process generated new residual austenite phase.
\end{abstract}

\section{Introduction}

Gear is the key basic part in machinery products. Practice showed that gear failure appeared on tooth surface primarily. So it was the basic scientific problem to improve tooth surface performance of gears [1]. 40Cr steel was widely used in manufacturing industry as a driving part (such as gear wheel and bearings). However, it was easy to wear and tear in working which makes part discard as useless. Therefore, keeping $40 \mathrm{Cr}$ steel work piece away from the failure caused by corrosion, wear, oxidation, and fatigue is always an attractive objective [2].

The use of alloying for improving the properties of gear surface had been studied and developed widely because the strength of the material surface, wear, and fatigue strength properties could be improved significantly. But elements, processes, and mechanisms of alloying were not the same based on different materials [3, 4]. Cr was usually used as an alloying element to join into steel and alloys. Chrome plating was widely used because of higher hardness, good wear and corrosion resistance, and low cost.

High-current pulsed electron beam (HCPEB) was a new surface processing technology. When high energy density electron beam acted on the material surface, the coating alloy layer was melted, and substrate surface micromelting occurred. Coated alloy formed metallurgical combination with surface alloy layer due to diffusion melt into internal metal substrates, which made big changes in the material's surface properties, such as high hardness, high wear resistance, and strong corrosion resistance [5].

Therefore, here hard chrome plating was selected as precoating on $40 \mathrm{Cr}$ then dealt with electron beam. Excellent surface overall performance was expected to obtain.

\section{Materials and Methods}

2.1. Preparation of Specimen. $40 \mathrm{Cr}$ was chosen as experiment material (the chemical composition is $0.40 \mathrm{wt}-\% \mathrm{C}, 0.8 \mathrm{wt}-$ $\% \mathrm{Cr}, \mathrm{Ni} \leq 0.30 \mathrm{wt}-\%, 0.23 \mathrm{wt}-\% \mathrm{Si}, 0.7 \mathrm{wt}-\% \mathrm{Mn}$, and $\mathrm{Fe}$ balance). The heat treatment pattern involved the first $850^{\circ} \mathrm{C}$ quenching and then tempering at $300^{\circ} \mathrm{C}$. So its organizational form was tempered martensite.

2.2. Experimental Scheme. The orthogonal experiment was taken and three factors were selected: electron beam accelerating voltage, pulse frequency, and film thickness. Alloying process was investigated on the basis of surface morphology, element diffusion, and microstructural changed. The precoating thickness was selected as $1 \mu \mathrm{m}, 2 \mu \mathrm{m}$, and $3 \mu \mathrm{m}$ because 


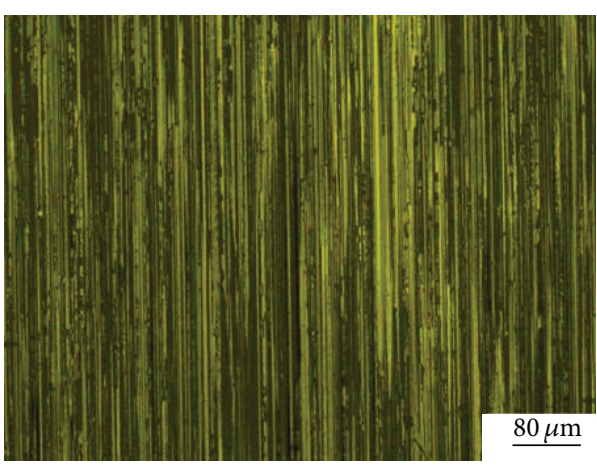

(a) Initial-only coating

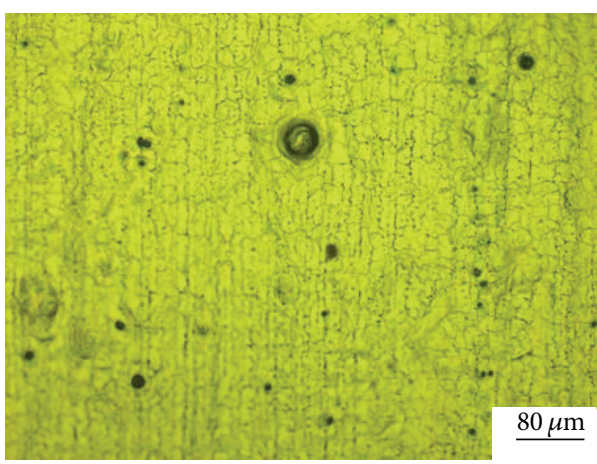

(c) $27 \mathrm{kV}-14$ times- $3 \mu \mathrm{m}$

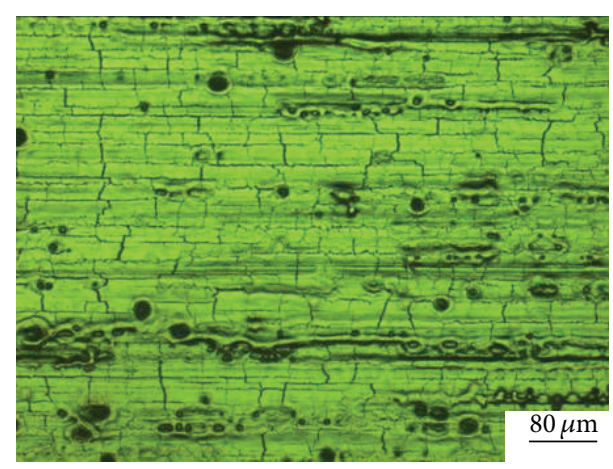

(b) $13 \mathrm{kV}$-14 times- $2 \mu \mathrm{m}$

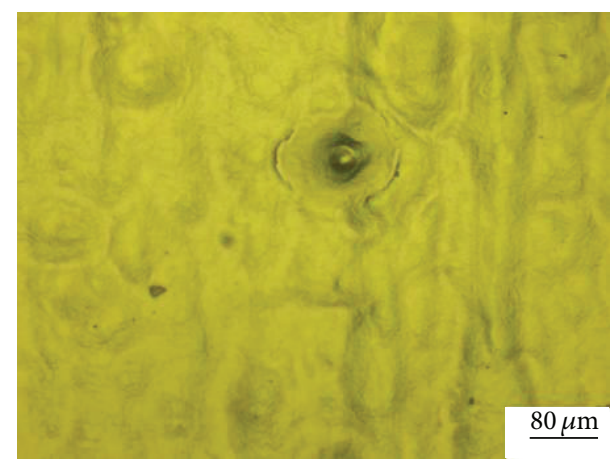

(d) $27 \mathrm{kV}-25$ times- $1 \mu \mathrm{m}$

FIGURE 1: Surface morphology after electron beam treatment.

TABLE 1: The level and factors of orthogonal experiment.

\begin{tabular}{lccc}
\hline Level & $\begin{array}{c}\text { Accelerating } \\
\text { voltage }(\mathrm{kV})\end{array}$ & $\begin{array}{c}\text { Pulse frequency } \\
\text { (times) }\end{array}$ & Film thickness $(\mu \mathrm{m})$ \\
\hline 1 & 13 & 3 & 1 \\
2 & 20 & 14 & 2 \\
3 & 27 & 25 & 3 \\
\hline
\end{tabular}

electron beam melting depth was not more than $3 \mu \mathrm{m}$ [6]. Influencing factors and levels were shown in Table 1.

Coating specimens were irradiated with electron beam equipment "RITM-2M", which was made in Russia. It had the operating parameters as follows: electron energy $10-40 \mathrm{keV}$, pulse duration $5-10 \mathrm{~ms}$, peak current density $1-6 \mathrm{~J} / \mathrm{cm}^{2}$, and cross-section area $30 \mathrm{~cm}^{2}$.

2.3. Organization and Performance Testing. The surface topography was examined using an Axio Imager A10 optical microscope and a JSM-6460LV scanning electron microscope. The chemical composition was studied by using DX2500 X-ray diffraction.

\section{Results and Discussion}

3.1. Surface Topography. The coating surface morphology before and after electron beam treatment was shown in Figure 1. Figure 1(a) was the chromium plating layer after machining, where mechanical wear scar dwelt on surface.
The crater could be observed on surface after electron beam irradiation, which was a typical feature of electron beam treatment [6]. The crack could be observed clearly on surface which could be caused by tensile stress.

Figure 1(b) showed the surface morphology of the voltage $13 \mathrm{kV}$, irradiation 14 times, and coating $2 \mu \mathrm{m}$. The mechanical grinding scar of the surface got some heal. Theoretically speaking, material surface melted quickly under electron beam irradiation, then molten metal flowed from the peak of the surface to the depressions rapidly on microscopic [7].

With increasing of accelerating voltage, the wear scar morphology was less clear and smoothing effect was more obvious. The crack became smaller with the acceleration voltage and the number of pulses increases. Figure 1(c) showed the surface morphology under the condition that the voltage was $27 \mathrm{kV}$, radiation 14 times, and coating depth $3 \mu \mathrm{m}$.

The surface cracks were not observed under the condition that voltage was $27 \mathrm{kV}$, radiation 25 times, and coating depth $1 \mu \mathrm{m}$, as shown in Figure 1(d).

The reason could be a result of the combined action of several factors. (1) High-energy electron beam was deposited on the surface of the material, which caused the metal surface layer of vaporization and enhanced diffusion [8]. So the chromium content of thin layer reduced or even disappeared. (2) The rapid heating of electron beam treatment caused thermal expansion, eventually rendering the surface compressive residual stress distribution [9]. (3) Chromium layer was in electron beam irradiation remelting zone and had completely fused with the base metal. 


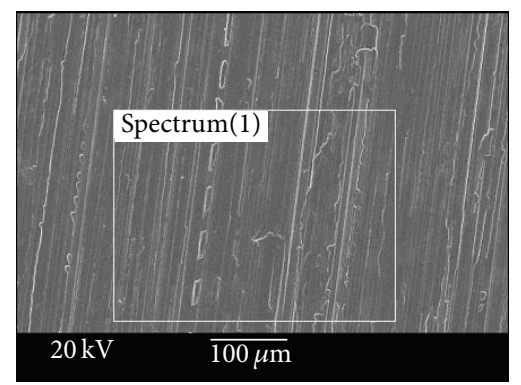

\begin{tabular}{ccc}
\hline Element & Weight\% & Atomic\% \\
\hline CrK & 100.00 & 100.00 \\
\hline Totals & 100.00 & \\
\hline
\end{tabular}

(a) Chromium plating $2 \mu \mathrm{m}$ surface spectrum before electron beam treatment

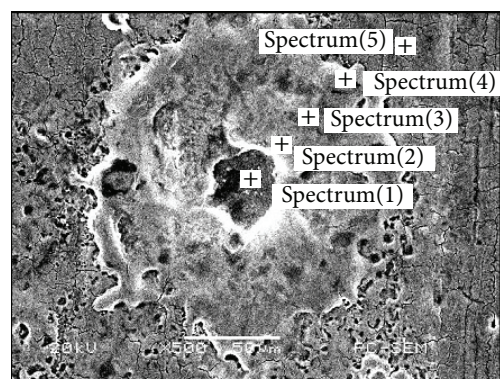

\begin{tabular}{ccc}
\hline Spectrum & $\mathrm{Cr}$ & $\mathrm{Fe}$ \\
\hline Line spectrum(1) & 3.57 & 96.43 \\
Line spectrum(2) & 14.13 & 85.87 \\
Line spectrum(3) & 26.31 & 73.69 \\
Line spectrum(4) & 48.64 & 51.36 \\
Line spectrum(5) & 96.70 & 3.30 \\
\hline
\end{tabular}

(b) Surface spectroscopy after $13 \mathrm{kV}-14$ times- $2 \mu \mathrm{m}$ parameters treated

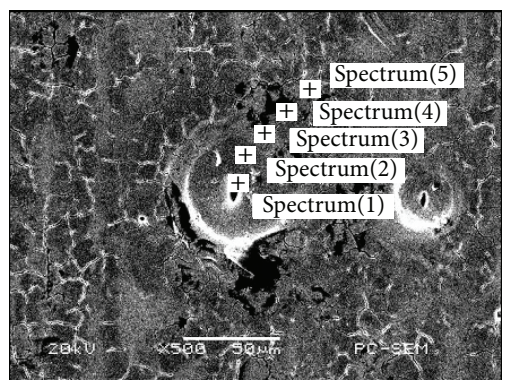

\begin{tabular}{ccccc}
\hline Spectrum & $\mathrm{S}$ & $\mathrm{Cr}$ & $\mathrm{Mn}$ & $\mathrm{Fe}$ \\
\hline Line spectrum(1) & 4.58 & 0.79 & 78.88 & 15.75 \\
Line spectrum(2) & & 2.35 & & 97.65 \\
Line spectrum(3) & & 14.88 & & 85.12 \\
Line spectrum(4) & & 61.17 & & 38.83 \\
Line spectrum(5) & & 52.84 & & 47.16 \\
\hline
\end{tabular}

(c) Surface spectroscopy after $20 \mathrm{kV}-25$ times- $2 \mu \mathrm{m}$ parameters treated

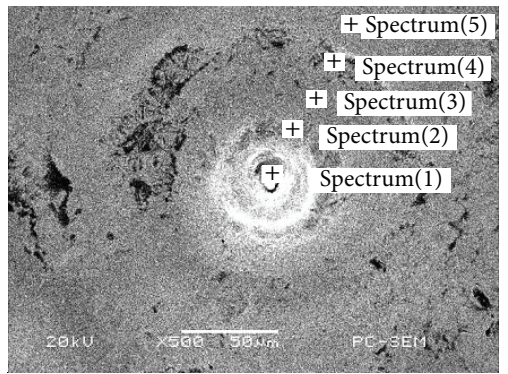

\begin{tabular}{ccccc}
\hline Spectrum & $\mathrm{S}$ & $\mathrm{Cr}$ & $\mathrm{Mn}$ & $\mathrm{Fe}$ \\
\hline Line spectrum(1) & 16.26 & 2.65 & 26.84 & 54.25 \\
Line spectrum(2) & & 3.77 & & 96.23 \\
Line spectrum(3) & & 3.15 & & 96.85 \\
Line spectrum(4) & & 9.61 & & 90.39 \\
Line spectrum(5) & & 9.28 & & 90.72 \\
\hline
\end{tabular}

(d) Surface spectroscopy after $27 \mathrm{kV}-25$ times- $1 \mu \mathrm{m}$ parameters treated

FIGURE 2: Spectroscopy analysis results of surface crater.

3.2. Surface Energy Spectrum Analysis. Figure 2 showed surface energy spectrum analysis of the electron beam processing under the part parameters. As shown in Figure 2(a), plating surface was completely a Cr element before electron beam treatment. The Crater morphology was observed on the surface after electron beam treatment. The melting pit of representative specimen was selected to perform energy spectrum analysis and element diffusion was observed from the melt hole center location to the surface.

The analysis results of 5 points were shown in Figure 2(b) from the melting pit center to the material surface at electron beam parameters $13 \mathrm{kV}$ voltage, irradiation 14 times, and plating thickness $2 \mu \mathrm{m}$. Cr elements' concentration of the points 1-4 was gradually increasing from melting pit center location to the material surface. Fe elements showed opposite distribution. The points 1, 2, 3, and 4 were in the melting pit eruption position, so Fe matrix elements were brought to the surface by volcanic crater eruption, which showed high concentration of center and low distribution of edge. Element concentrations of $\mathrm{Cr}$ and Fe varied widely from the measuring point 4 to 5 , which may be because the measuring point 5 was outside the area impact crater eruption. 
Figure 2(c) showed test result at $20 \mathrm{kV}$ voltage, irradiation 25 times, and plating thickness $2 \mu \mathrm{m}$. The element distribution trend was the same as shown in Figure 2(b). But the surface portion of $\mathrm{Cr}$-Fe element concentration decreased about $95 \%$ than the previous specimen. It maybe because that diffusion of elements was promoted with the increasing of radiation voltage and frequency.

Figure 2 (d) showed the analysis results at $27 \mathrm{kV}$ voltage, irradiation 25 times, and the plating thickness $1 \mu \mathrm{m}$. Fe concentration of the specimen improved greatly after treatment. There may be several reasons as follows. Firstly, as the radiation voltage and frequency increased, the diffusion between the elements was further promoted. Secondly, the chromium layer and substrate of the molten layer produced by electron beam irradiation had been completely melted, which caused content of $\mathrm{Cr}$ reducing in surface because they spread to subsurface. Finally, high energy of electron beam depositing on the material surface could lead to vaporization and enhanced diffusion of the surface layer metal and other physical chemical phenomena, which makes chromium content of thin layer reduced or even disappeared.

3.3. Morphologies and EDX Analysis in Section. The specimen discussed previously was selected to perform interface energy spectrum analysis to explore element diffusion and the effect of alloying after the electron beam processing, as shown in Figure 3. Plating specimens were shown in Figure 3(a) before electron beam processing. Cr-Fe element intensity distribution was very steep at the interface curve, and diffusion almost did not happened between $\mathrm{Cr}$ and Fe element.

The molten layer formed after electron beam irradiation could be clearly observed in Figures 3(b), 3(c), and 3(d). Chromium layer which had completely melted fused together with the portion of melted base metal. In addition, the grain refinement of base material after electron beam treatment could be observed.

When voltage was $13 \mathrm{kV}$, irradiation was 14 times, and the plating thickness was $2 \mu \mathrm{m}$, it was shown that the elements $\mathrm{Cr}-\mathrm{Fe}$ diffusion layer depth was about $2.5 \mu \mathrm{m}$ in spectrum analysis, while the molten layer coating was about $2 \mu \mathrm{m}$ depth and grain refinement layer depth was about $1.8 \mu \mathrm{m}$, as was shown in Figure 3(b). The Fe element was not detected on surface maybe because of its low concentration, which was confirmed by the surface EDS analysis results of the previous paper.

When the voltage was $20 \mathrm{kV}$, irradiation was 25 times, and the plating thickness was $2 \mu \mathrm{m}$, it was shown that the elements Cr-Fe diffusion layer depth was about $5.5 \mu \mathrm{m}$ in spectrum analysis. The molten layer coating was about $2.7 \mu \mathrm{m}$ depth and grain refinement layer depth was about $2 \mu \mathrm{m}$, as was shown in Figure 3(c). This was because the accelerating voltage, increasing pulse number, enhanced deposition energy of surface unit area, which prompted Fe element in the substrate diffusing to the surface of coating.

When the voltage was $27 \mathrm{kV}$, irradiation was 25 times, and the plating thickness was $1 \mu \mathrm{m}$, because of the higher accelerating voltage and thinner plating Cr layer, the molten layer coating was about $3.5 \mu \mathrm{m}$ depth and grain refinement layer depth was about $3.8 \mu \mathrm{m}$. The depth of the diffusion layer was more than $8 \mu \mathrm{m}$, and the intensity in the surface layer containing Fe was greater than $\mathrm{Cr}$.

Thus, it was easy to summarize that with the increasing of electron beam acceleration voltage, pulses number, depth of the surface molten layer, grain refinement, and diffusion layer was increased gradually to obtain a good effect of alloying. The interdiffusion between coating and the matrix elements turned their mechanical bond into metallurgical bond. The electron-beam remelting and rapid cooling could cause grain refinement near the surface. And diffusion of elements caused solid solution strengthening. All these things provided conditions for improving surface properties of material.

3.4. XRD Analysis. Figure 4 shows that XRD diffraction spectrum of specimens corresponds to electron beam treatment. $40 \mathrm{Cr}$ original specimen was shown in Figure 4(a) before electron beam treatment and XRD diffraction spectrum of different thickness chromium layer specimens. The diffraction peak height of the specimen after plating was lower than before, and width increased significantly. The value of peak width achieved maximum when the coating thickness was $3 \mu \mathrm{m}$.

XRD diffraction spectrum of specimens was shown in Figure 3(b) with different $\mathrm{Cr}$ layer thickness and pulses number under $13 \mathrm{kV}$ voltage. Compared with the samples of only electroplating sample, the diffraction peak height was improved to some extent, and the diffraction peak width became narrow down. And it was more obvious with the increasing of the pulses number. It performed most obviously in the (110) lattice plane, which showed that as the integrity of the grain after the electron beam treatment improves, grain grows. When the Cr layer thickness was $1 \mu \mathrm{m}$ and $2 \mu \mathrm{m}$, the corresponding diffraction spectrum appeared new characteristic peaks [10]. So new phase at produced, which was residual austenite, through analysis.

XRD diffraction spectrum of specimens was shown in Figure 4 with different $\mathrm{Cr}$ layer thickness and pulses number under $20 \mathrm{kV}$ voltage. It was found that the surface crystal of specimen occurred preferred orientation from the original (110) lattice plane more than that from the (200). At the same time, the residual austenite phase appeared on surface of the chromium layer thickness $1 \mu \mathrm{m}$ and $2 \mu \mathrm{m}$.

When accelerating voltage was increased to $27 \mathrm{kV}$, as shown in Figure 4(d), the preferred orientation of (200) lattice plane disappeared. The diffraction peak of residual austenite phase became very high at the irradiation of 25 pulse number, showing that the content increased significantly as a result of the very thin chromium layer at the moment. Within the scope of the electron beam melting layer, the deposited energy of electron beam bombarding material was sufficient to make the chromium layer and the substrate realized the full metallurgical melting of the matrix and coating metal under the action of mechanical stir at high voltage and pulse frequency. At the same time the austenite retained down and formed residual austenite under the rapid cooling speed.

By comparing the XRD diffraction of the orthogonal experiment specimens comprehensively, it could be found that residual austenite phase was often produced in the lower thickness chromium layer and its content also gradually 

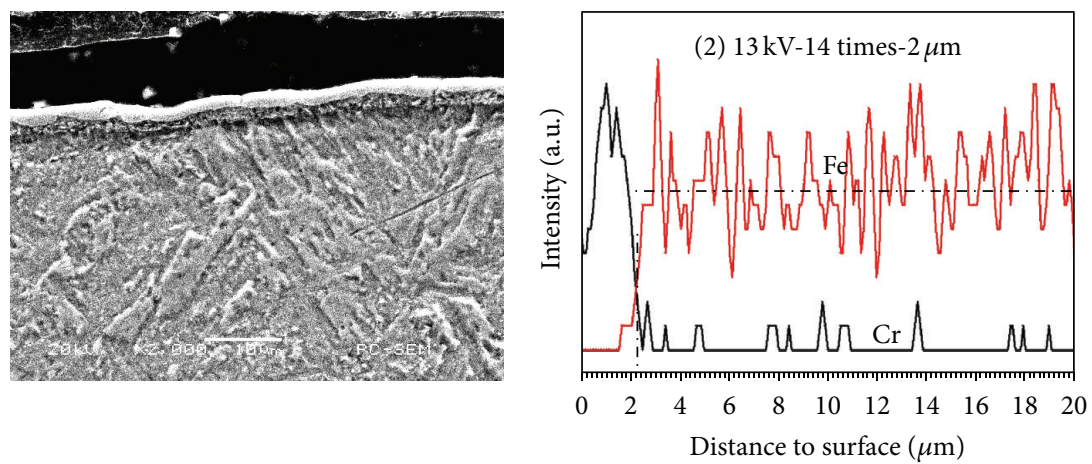

(a) Initial- $3 \mu$ m coating
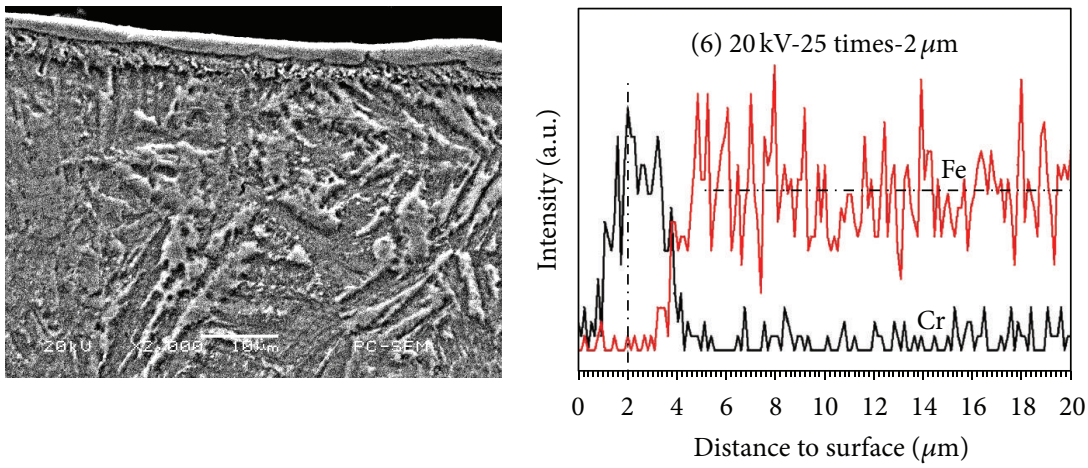

(b) $13 \mathrm{kV}-14$ times- $2 \mu \mathrm{m}$
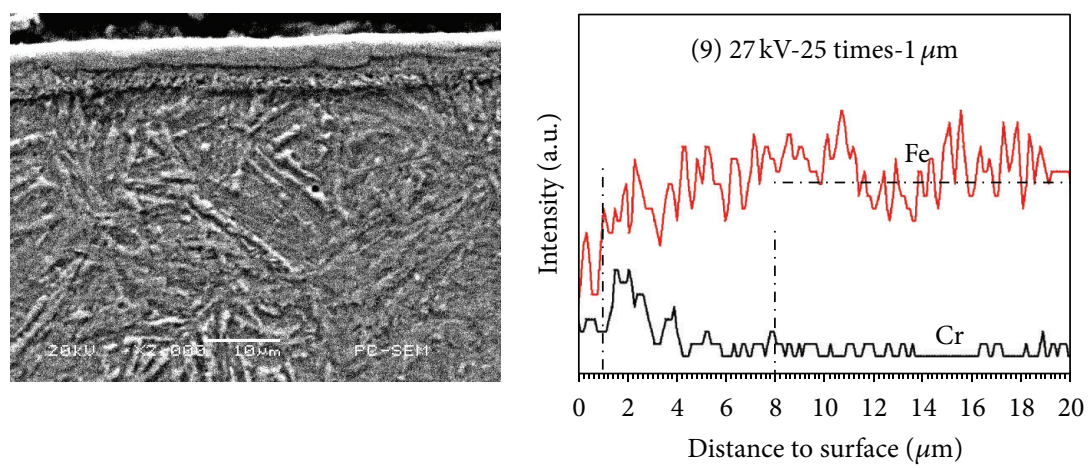

(c) $20 \mathrm{kV}$-25 times- $2 \mu \mathrm{m}$
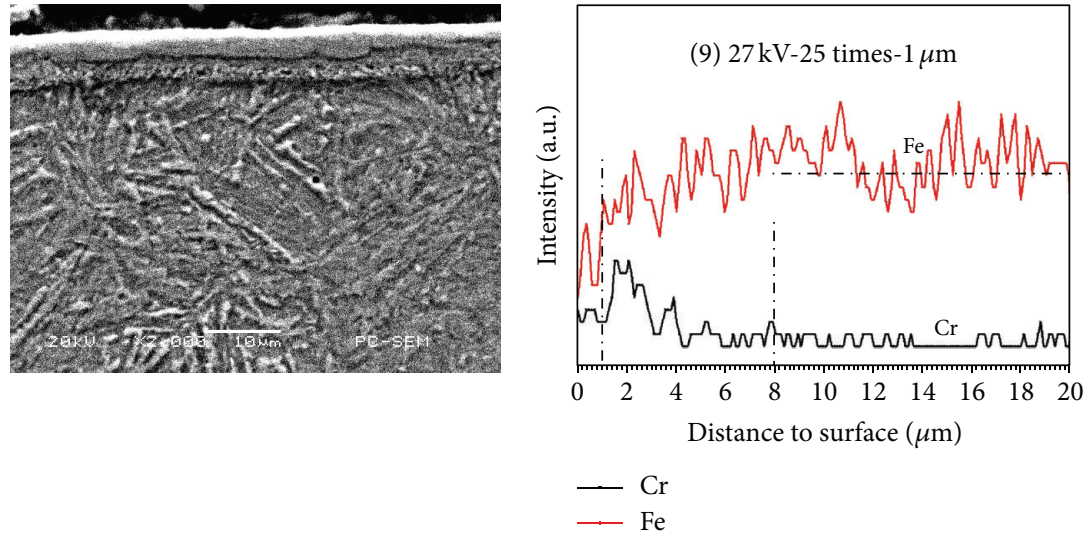

(d) $27 \mathrm{kV}-25$ times- $1 \mu \mathrm{m}$

Figure 3: Cross-section morphology and spectral analysis. 

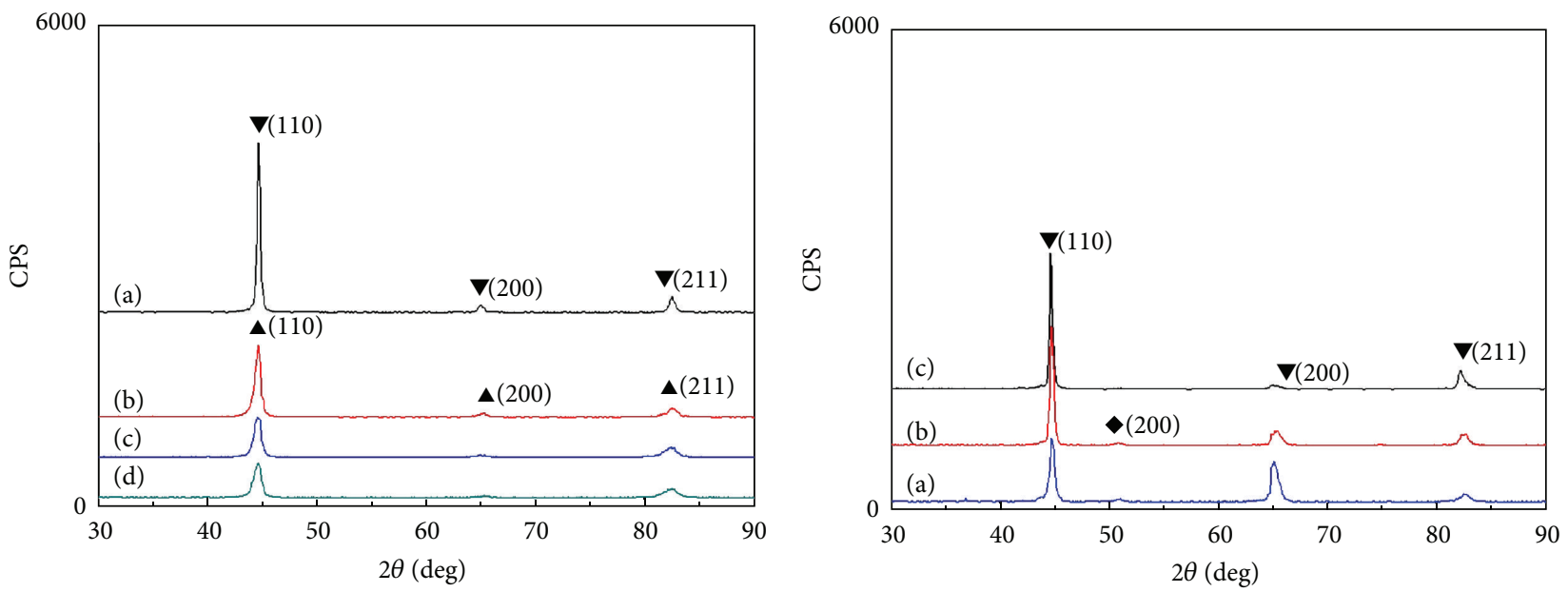
(a) - Initial
$\boldsymbol{\nabla}-\mathrm{Fe}$
(b) - $1 \mu \mathrm{m}$ coating
(c) $-2 \mu$ m coating
(d) - $3 \mu$ m coating

(a)

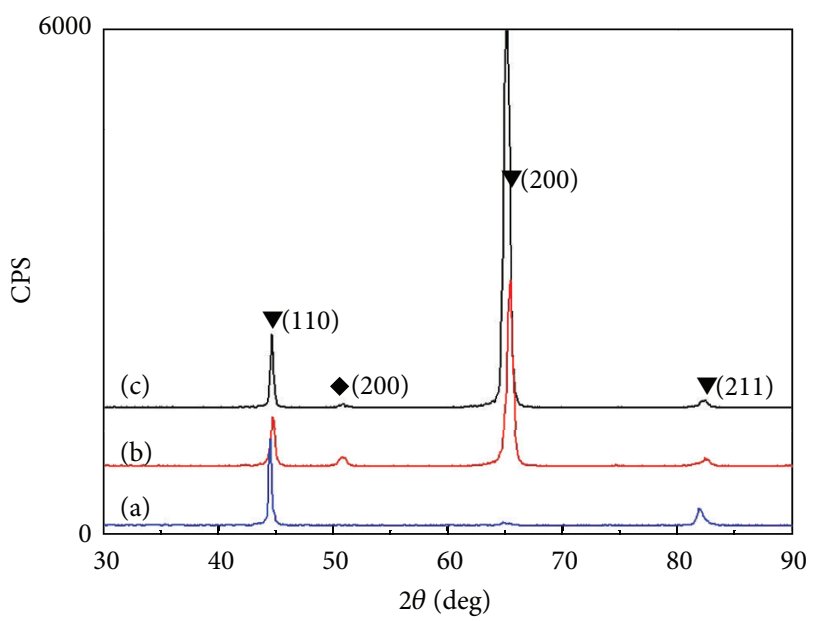
(a) $-20 \mathrm{kV}, 3$ pulses, $3 \mu \quad \boldsymbol{\nabla}$-Fe-Cr
(b) $-20 \mathrm{kV}, 14$ pulses, $1 \mu \quad-\mathrm{FeCr}^{0.29} \mathrm{Ni}^{0.16} \mathrm{C}^{0.06}$
(c) $-20 \mathrm{kV}, 25$ pulses, $2 \mu$

(c)
(a) — $13 \mathrm{kV}, 3$ pulses, $1 \mu$
(b) $-13 \mathrm{kV}, 14$ pulses, $2 \mu$
(c) $-13 \mathrm{kV}, 25$ pulses, $3 \mu$

(b)

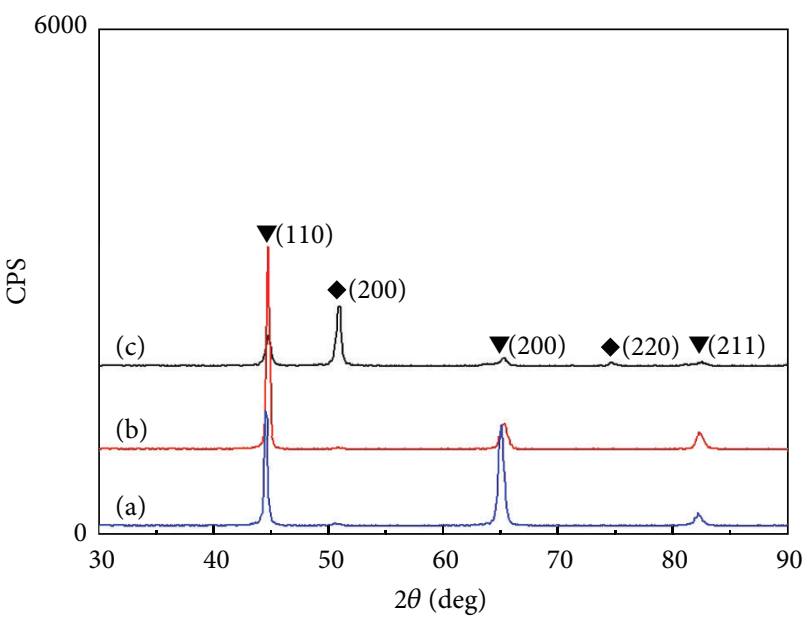
(a) $-27 \mathrm{kV}, 3$ pulses, $2 \mu \quad \boldsymbol{\nabla}$-Fe-Cr
(b) $-27 \mathrm{kV}, 14$ pulses, $3 \mu \quad-\mathrm{FeCr}^{0.29} \mathrm{Ni}^{0.16} \mathrm{C}^{0.06}$
(c) $-27 \mathrm{kV}, 25$ pulses, $1 \mu$

(d)

FIgURE 4: XRD diffraction spectrum.

increased with the increasing of acceleration voltage and pulse numbers. When the acceleration voltage reaches $27 \mathrm{kV}$, pulse number was 25 times, and coating thickness was $1 \mu \mathrm{m}$, the surface residual austenite phase generated mostly [11].

By comparing the specimens treated with three different groups of accelerating voltages, it could be found that diffraction peaks had a certain degree of excursion to the right after electron beam treatment, indicating that the existing compressive stress or tensile stress releases. And it illustrated that the surface tensile stress could be reduced indirectly with the increasing of pulse number and make the surface present residual compressive stress state, finally. The comprehensive performance of surface could also be improved significantly.

\section{Conclusion}

$40 \mathrm{Cr}$ was precoated with electroplating hard chromium, and orthogonal experiment was used to realize the electron beam alloying processing. The conclusions could be drawn as following.

(1) After the coating surface was treated with electron beam, a certain disagree of microcrack appeared on the surface, which became less and even disappeared with the increasing of accelerating voltage and pulse frequency.

(2) After electron beam treatment, it was promoted that metal matrix elements spread to the coating surface. 
With increasing of irradiation voltage and pulse frequency, the diffusion of surface element became stronger.

(3) The alloying layer depth could reach $8 \mu \mathrm{m}$ treated by electron beam alloying maximum. And melting layer and grain refinement layer depth were increased gradually with the increasing of accelerating voltage and pulse frequency.

(4) Contrasting with the original only electroplated, the chromium layer grain phases of specimens treated by electron beam were significantly larger. The residual austenite was produced on the surface. And the diffusion caused by electronic beam alloying could not only form solid solution making crystal lattice distorted, but also produce complex internal stress changes.

\section{Acknowledgments}

The work has been supported by the National Natural Science Foundation of China (51275548), Chongqing Science and Technology Commission (cstc2012jjB0002 and cstc2012ggyyjs70019), and Innovation team of Chongqing Education Commission.

\section{References}

[1] D. T. Jelaska and S. Podrug, "Gear tooth root fatigue assessments by estimating the real stress cycle," in Proceedings of the International Design Engineering Technical Conferences \& Computers and Information in Engineering Conference (ASME '07), pp. 887894, September 2007.

[2] J. J. Hu, G. B. Zhang, H. B. Xu et al., "Microstructure characteristics and properties of $40 \mathrm{Cr}$ steel treated by high current pulsed electron beam," Materials Technology, vol. 27, no. 4, pp. 300-303, 2012.

[3] Z. Tiejun, G. Bo, T. Xiaomei et al., "Modification and alloying of high purity magnesium surface with high current pulsed electron beam," Chinese Journal of Vacuum Science and Technology, vol. 28, no. 1, pp. 11-15, 2008.

[4] H. Jianjun, Z. Genbao, C. Yuanfang et al., "Surface property of $40 \mathrm{Cr}$ alloyed $\mathrm{Al}$ with high current pulsed electron beam," Materials Review, vol. 26, no. 10, pp. 9-11, 2012.

[5] K. Lee, K. Euh, D.-H. Nam, S. Lee, and N. J. Kim, "Wear resistance and thermal conductivity of Zr-base amorphous alloy/ metal surface composites fabricated by high-energy electron beam irradiation," Materials Science and Engineering A, vol. 449-451, pp. 937-940, 2007.

[6] C. Yuan-fang, X. Hong-bin, H. Jianjun et al., "Effect of HCPEB on frictional wear resistance of $3 \mathrm{Cr} 2 \mathrm{~W} 8 \mathrm{~V}$ mould stell," Journal of Wuhan University of Technology, vol. 33, no. 11, pp. 19-23, 2011.

[7] H. Jianjun, Z. Genbao, X. Hongbin et al., "Gear bending fatigue strength with pulsed electron beam on different finished surface," China Mechanical Engineering, vol. 24, no. 3, pp. 380-385, 2013.

[8] G. E. Ozur, D. I. Proskurovsky, V. P. Rotshtein, and A. B. Markov, "Production and application of low-energy high-current electron beams," Laser and Particle Beams, vol. 21, no. 2, pp. 157-174, 2003.
[9] K. Jun, L. Gang, X. Jun, J. Mengdong, and L. Zigang, "Alloying $\mathrm{Al}$ on the surface of magnesium AZ31 alloy by high current pulsed electronic beam," Special Casting and Nonferrous Alloys, vol. 29, no. 11, pp. 1064-1067, 2009.

[10] J. Zou, K. Zhang, C. Dong et al., "Selective surface purification via crater eruption under pulsed electron beam irradiation," Applied Physics Letters, vol. 89, no. 4, Article ID 041913, 3 pages, 2006.

[11] M. Rongshan, Study on Electron Beam Alloying Process and Properties of 40Cr Surface D, Chongqing University of Technology, Chongqing, China, 2013. 

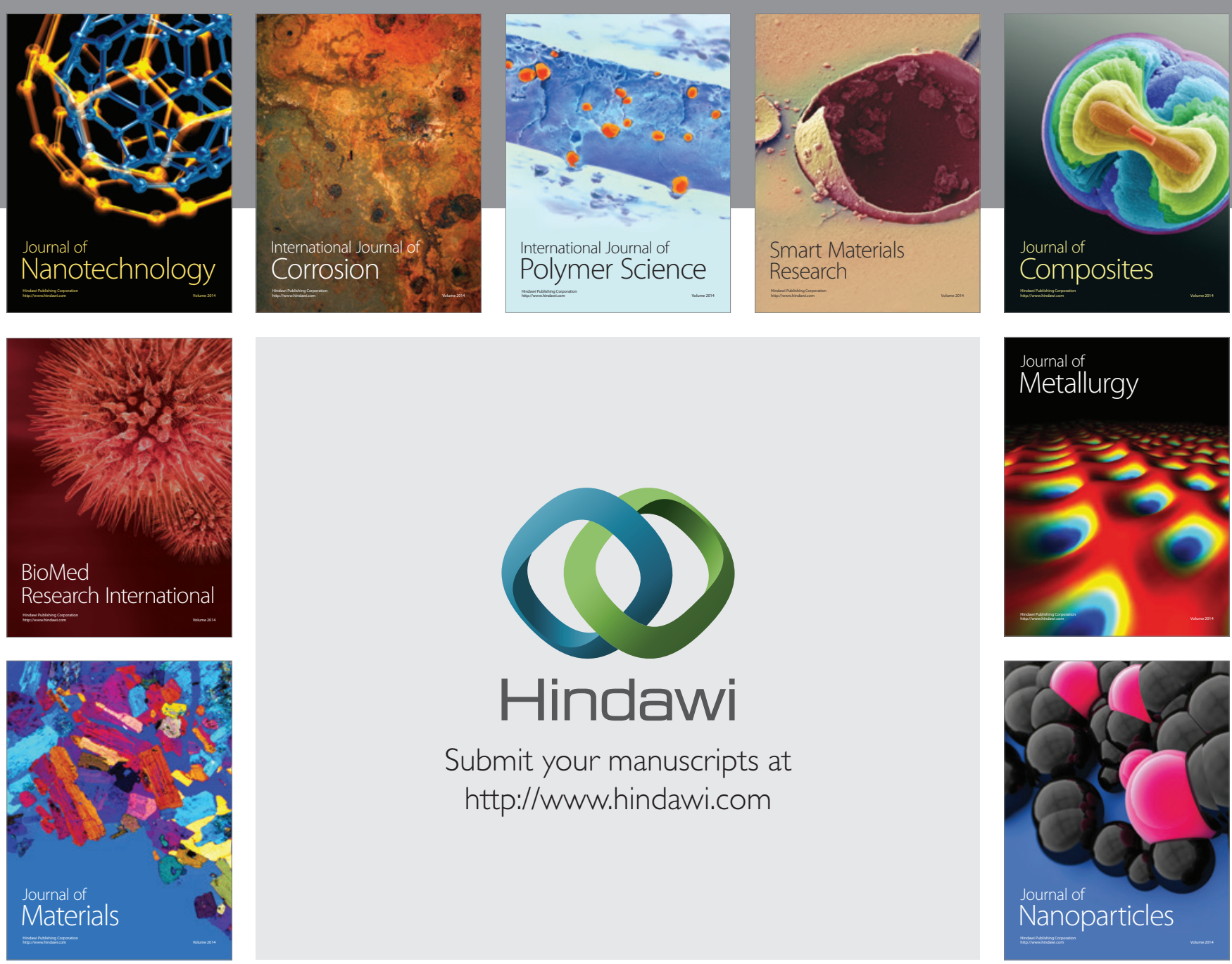

Submit your manuscripts at http://www.hindawi.com
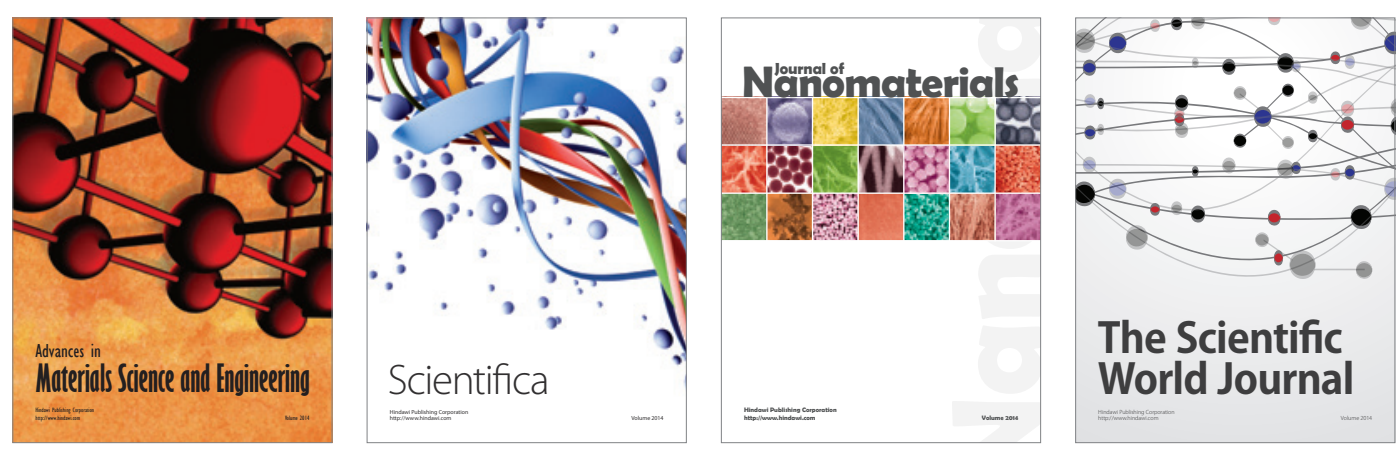

\section{The Scientific World Journal}
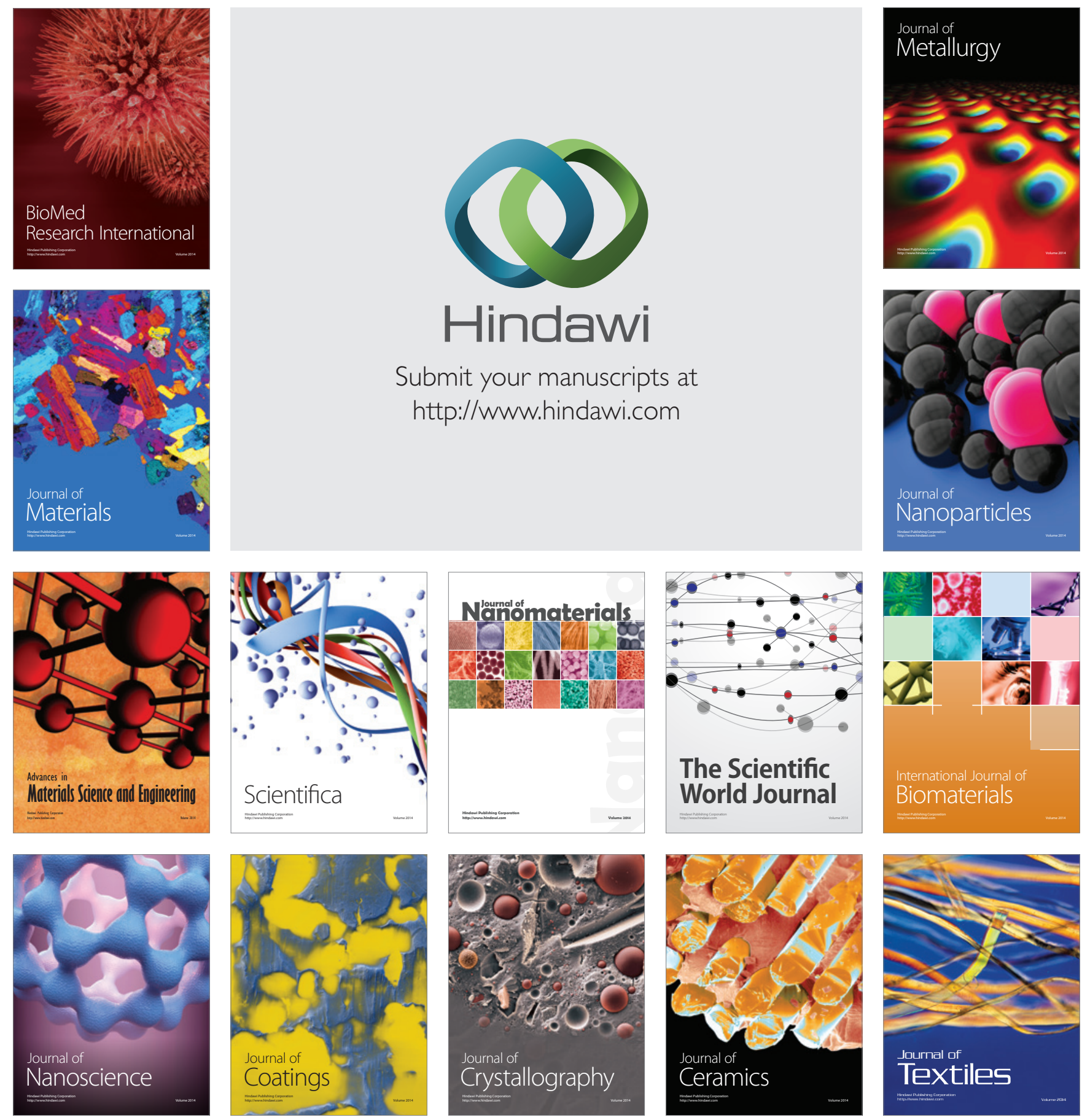